\title{
A New Approach to Study the Physical Stability of Monoclonal Antibody Formulations - Dilution from a Denaturant
}

\author{
Hristo Svilenov ${ }^{1 \star}$, Lorenzo Gentiluomo ${ }^{1,2}$, Wolfgang Friess ${ }^{1}$, Dierk Roessner ${ }^{2}$, Gerhard Winter ${ }^{1}$
}

${ }^{1}$ Ludwig Maximilians-Universität München, Department of Pharmacy, Pharmaceutical Technology and Biopharmaceutics, Butenandstr. 5, 81377 Munich, Germany

${ }^{2}$ Wyatt Technology Europe GmbH, Hochstrasse 12a, 56307 Dernbach, Germany

*Corresponding author: hrisph@cup.uni-muenchen.de

Accepted manuscript published with Green Open Access as:

Svilenov, H., Gentiluomo, L., Friess, W., Roessner, D. and Winter, G., 2018. A New Approach to Study the Physical Stability of Monoclonal Antibody Formulations-Dilution From a Denaturant. Journal of pharmaceutical sciences, 107(12), pp.3007-3013.

https://doi.org/10.1016/j.xphs.2018.08.004 


\begin{abstract}
The early-stage assessment of the physical stability of new monoclonal antibodies in different formulations is often based on high-throughput techniques that suffer from various drawbacks. Accordingly, new approaches that facilitate the protein formulation development can be of high value to the industry. In this study, a dynamic light scattering (DLS) plate reader is used to measure the aggregation (by means of the increase in the hydrodynamic radius $\left(R_{h}\right)$ ) of monoclonal antibody samples that were subject to incubation and subsequent dilution from different concentrations of a denaturing agent, i.e. guanidine hydrochloride. The increase in the $R_{h}$ of the protein samples is dependent not only on the denaturant concentration used but also on the buffer in which the incubation/dilution was performed. We also compare the aggregation after dilution from a denaturant with other high-throughput stability-indicating methods and find good agreement between the techniques. The proposed approach to probe the physical stability of monoclonal antibodies in different formulation conditions offers a unique combination of features - it is isothermal, probes both the resistance to denaturant-induced unfolding and the colloidal protein stability, it is entirely label-free, does not rely on complex data evaluation, and requires very short instrument measurement time on standard equipment.
\end{abstract}

\title{
Keywords
}

Protein aggregation, Protein formulation, Protein folding/refolding, Light scattering (dynamic), Stability, Fluorescence spectroscopy
Abbreviations
$\mathrm{C}_{\mathrm{m}}-$ concentration of denaturant required to unfold $50 \%$ of the protein;
$d G$ - the Gibbs free energy of unfolding (apparent values in this work);
DLS - dynamic light scattering;
GuHCl - guanidine hydrochloride;
ICD - isothermal chemical denaturation;
mAb - monoclonal antibody;
$T_{m}$ - protein melting temperature; 


\section{Introduction}

One of the goals in the (pre-)formulation development of new monoclonal antibodies (mAbs) is to find conditions that provide high protein physical stability. Such studies can be performed with highthroughput techniques which can be classified as isothermal or non-isothermal. Two of the most widely used non-isothermal techniques are differential scanning calorimetry (DSC) and differential scanning fluorimetry (DSF) ${ }^{1-4}$. In general, non-isothermal techniques suffer from drawbacks related to the heating of the sample. For example, aggregation during temperature ramps often hinders the thermodynamic evaluation of DSC data and affects the accuracy of the determined protein melting temperatures from both DSC and DSF ${ }^{5,6}$. Furthermore, non-isothermal techniques suffer from the fact that the properties of many excipients (e.g. the $\mathrm{pH}$ of amine buffers like histidine) change during heating, which can affect the obtained stability rankings based on protein melting temperatures ${ }^{7}$.

Isothermal chemical denaturation (ICD) is a valuable technique that avoids the above-mentioned drawbacks of DSC and DSF 5,7 . Historically, ICD was not the method of choice for protein formulation studies mostly due to the tedious sample preparation ${ }^{8}$. These limitations of ICD have recently been overcome by the use of equipment that can (semi-)automatically prepare and measure protein samples containing varying concentrations of a denaturating agent $5,7-10$. However, the accurate thermodynamic evaluation of ICD data assumes that the protein unfolding process is fully reversible, the system is in equilibrium and the denaturation graph fits a known model (e.g. two-state, three-state unfolding, etc.) 11,12. A recent paper shows that neither reversibility nor equilibration times in an ICD experiment with mAbs are trivial ${ }^{11}$. In addition, multidomain proteins may also exhibit multiple transitions that can be close to each other or (partially) overlap which can introduce a large error to the parameters derived from the fit.

Last but not least, high-throughput DSF and ICD methods are usually based on intrinsic protein fluorescence measurements (i.e. observations due to a change in the tryptophan exposure after protein unfolding) $2,5,13$. This creates complications when no tryptophan is present or when the tryptophan in a certain protein domain is already solvent exposed in the native protein conformation.

Considering the above-mentioned issues, we saw a demand for novel approaches that can be used in a high-throughput manner to investigate the physical stability of new mAbs in different formulations. The hypothesis we present is that isothermal incubation and dilution of monoclonal antibodies from guanidine hydrochloride solutions with a certain concentration will lead to a substantial protein aggregation. Further, we propose that the amount and the size of the aggregates formed will depend on the formulation conditions and the physical stability of the mAbs (Fig 1) and that this aggregation will be in good agreement with other methods used to study the protein physical stability. Previously, dilution from a denaturant was used to probe the molten globule states and the stability during refolding of other proteins (e.g. human growth hormone ${ }^{14,15}$, lysozyme ${ }^{16}$, recombinant human gamma interferon ${ }^{17}$, and others $\left.{ }^{18-20}\right)$. However, previous work focuses mostly on proteins that are expressed as inclusion bodies in bacteria and the aim of such experiments was usually to achieve higher monomer yields after expression, solubilization and subsequent refolding. To best of our knowledge, we are the first to propose that the assessment of the aggregation after incubation and dilution from different concentrations of a denaturant can be used for high-throughput formulation studies of large proteins (i.e. mAbs, that are typically not expressed as inclusion bodies).

In this work, we use a dynamic light scattering plate reader to assess the aggregation (i.e. the increase in the hydrodynamic radius) of two mAbs after dilution from different concentrations of guanidine hydrochloride $(\mathrm{GuHCl})$ in different buffers. We confirm our hypothesis that conditions that provide higher physical stability of the protein will require higher $\mathrm{GuHCl}$ concentrations to induce protein aggregation after dilution of the denaturant. We also show that conditions that provide higher protein colloidal stability will result in a smaller increase of the $\mathrm{R}_{\mathrm{h}}$ after dilution from $\mathrm{GuHCl}$. We compare the proposed approach with other established high-throughput methods (e.g. DSF, ICD) to find agreement between the predictions. The method we investigate provides a unique combination of features - it is an isothermal technique that simultaneously probes the resistance to GuHCl-induced unfolding and the colloidal https://doi.org/10.1016/j.xphs.2018.08.004 
protein stability (i.e. the level of aggregation after dilution from $\mathrm{GuHCl}$ ). In addition, no complex data evaluation or a fitting to a certain protein unfolding model is required (in contrast to ICD). Additionally, the approach is label-free and does not rely on intrinsic protein fluorescence measurements (contrary to DSF and ICD). Finally, the proposed approach offers a high potential for scale down and full automation with the existing infrastructure in many protein formulation laboratories.

\section{Materials and Methods}

\section{Monoclonal Antibodies}

Both monoclonal antibodies (LMU-1 and PPI03) used in this work belong to the IgG1 subclass. SDSPAGE of the protein bulk shows only bands for the mAb monomer and mAb fragments. Relative monomer area of both bulks is $>99.5 \%$, measured by size exclusion chromatography.

The mAb buffer was exchanged by dialysis at $20-25{ }^{\circ} \mathrm{C}$ using Spectra/Por $\AA 8000$ MWCO dialysis tubing (Spectrum Laboratories Inc., Rancho Dominguez, USA). The sample to buffer ratio was 1:200 and two buffer exchanges were performed 3 and 8 hours after the beginning. After the last change, dialysis was continued for another 16 hours. The final buffers of both proteins contained $10 \mathrm{mM}$ citrate or $10 \mathrm{mM}$ histidine with $\mathrm{pH} 5$ or 5.75 . Also, all LMU- 1 samples contained $0.05 \% \mathrm{w} / \mathrm{v}$ polysorbate 20 , while all PPI03 samples were free of surfactants.

For the experiment where we compare the effect of additives, $2 x$ stock solution of the respective additive (i.e. sucrose, trehalose, arginine hydrochloride or proline) in the respective buffer were mixed with the protein to obtain a final concentration of $200 \mathrm{mM}$ sucrose, $200 \mathrm{mM}$ trehalose, $200 \mathrm{mM}$ arginine hydrochloride or $200 \mathrm{mM}$ proline. For the final protein concentrations in the different experiments see the Results and Discussion section.

The protein concentration was measured with a Nanodrop 2000 (Thermo Fisher Scientific, Wilmington, USA). Reagent chemicals from the highest grade available were purchased from Sigma Aldrich (Steinheim, Germany) or VWR International (Darmstadt, Germany). Highly purified water (HPW) was used for the preparation of all buffers.

\section{Sample Preparation, Incubation and Dilution from Different Concentration of Guanidine Hydrochloride}

Samples containing protein (LMU-1 or PPI03) and 0, 1, 2, 3, or $4 \mathrm{M}$ guanidine hydrochloride in buffer were prepared by mixing $25 \mu \mathrm{L}$ of protein solution in the respective buffer (or in the respective buffer with an additive i.e. $200 \mathrm{mM}$ sucrose, $200 \mathrm{mM}$ trehalose, $200 \mathrm{mM}$ arginine hydrochloride or $200 \mathrm{mM}$ proline) with $75 \mu \mathrm{L}$ of guanidine hydrochloride solution in the same buffer (or in the same buffer containing an additive - see above). After 24 hours of incubation with the denaturant, the samples were diluted 10 times by rapid addition of the respective buffer (or the respective buffer containing an additive - see above) and incubated for another 24 hours. For protein concentration in the final samples after the last dilution refer to the Results and Discussion section. The $\mathrm{pH}$ of the samples was controlled at each step using an appropriately calibrated InLab ${ }^{\mathrm{TM}}$ Nano $\mathrm{pH}$ Electrode with a SevenEasy $\mathrm{pH}$ meter (Mettler Toledo, Germany). The pH reported is the $\mathrm{pH}$ of the samples after the final dilution from the denaturant $( \pm 0.1 \mathrm{pH}$ units). Finally, the samples were centrifuged at $8200 \times \mathrm{g}$ for 10 minutes and measured with a DLS plate reader (see next sections). All experiments were performed in triplicates. 


\section{Isothermal Chemical Denaturation (ICD)}

Protein in formulation buffer and various amounts of buffer and $6 \mathrm{M}$ guanidine hydrochloride solution in the respective buffer were combined in a 384- non-binding well plate (Corning, USA) using the Viaflo Assist pipetting station equipped with a 16-channel $12.5 \mu \mathrm{L}$ and a $125 \mu \mathrm{L}$ pipette (Integra Biosciences, Konstanz, Germany) as already described ${ }^{7}$ (Dilution schemes are available in the supplementary data as Tab S1 and S2). The $\mathrm{pH}$ of the samples was controlled after preparation as described in the previous section. Next, the well plate was sealed. After 24 hours incubation at room temperature, the protein fluorescence intensity at $330 \mathrm{~nm}$ and $350 \mathrm{~nm}$ was measured after excitation at $280 \mathrm{~nm}$ with a FLUOstar Omega microplate reader (BMG Labtech, Ortenberg, Germany). The intrinsic fluorescence intensity ratio F350/330 (the fluorescence intensity at $350 \mathrm{~nm}$ divided by the fluorescence intensity at $330 \mathrm{~nm}$ ) was plotted against the denaturant concentration to obtain isothermal chemical denaturation graphs. All samples were prepared in triplicates and the best fit to a three-state model of each replicate in the CDpal software was used to determine the apparent Gibbs free energy of unfolding (dG) and the denaturant concentration needed to unfold $50 \%$ of the protein $\left(\mathrm{Cm}_{\mathrm{m}}\right)$. Other unfolding models available in the CDpal software (e.g. two-state, three-state with dimerization of the intermediates, etc.) were also investigated but showed worse fit quality than the three-state model after an f-test comparison. The three-state model was also used by other groups to evaluate isothermal chemical denaturation data with mAbs ${ }^{11,21}$. Since all samples were evaluated with the three-state model, two $C_{m}$ values were determined $-C_{m 1}$ for the transition taking place at lower denaturant concentration and $\mathrm{C}_{\mathrm{m} 2}$ for the other transition.

\section{Dynamic Light Scattering (DLS)}

$25 \mu \mathrm{L}$ of each sample were pipetted in triplicates into a 384- clear bottom well plate (Corning, USA) and the plate was centrifuged at $2000 \mathrm{rpm}$ for 2 minutes using a Heraeus Megafuge 40 centrifuge equipped with an M-20 well plate rotor (Thermo Fisher Scientific, Wilmington, USA). Next, each well was capped with approximately $5 \mu \mathrm{l}$ of silicon oil and centrifuged again at $2000 \mathrm{rpm}$ for 2 minutes. 10 acquisitions of 10 seconds at $25^{\circ} \mathrm{C}$ were taken with the Dyna Pro II DLS plate reader (Wyatt Technology Europe, Dernbach, Germany). The Dynamics V7.8 software was used for all the calculations. The autocorrelation function (ACF) of each sample was calculated from the fluctuation of the light scattering intensity. Cumulant analysis was used to derive the apparent coefficient of self-diffusion (D) and the polydispersity index (PDI). The viscosity of each sample was measured with a falling ball viscosimeter, AMVn (Anton Paar $\mathrm{GmbH}$, Ostfildern-Scharnhausen, Germany). The Stokes-Einstein equation was used to calculate the apparent hydrodynamic radius $\left(R_{h}\right)$ at $25^{\circ} \mathrm{C}$ from the $\mathrm{D}$ and the sample viscosity. As an additional part of the data analysis, the sample size distribution was calculated from the regularization method. Unless otherwise stated, the $\mathrm{R}_{\mathrm{h}}$ values reported in this work are derived from the cumulant analysis.

To determine the interaction parameter $\left(\mathrm{k}_{\mathrm{D}}\right)$, different concentrations of LMU-1 (from 1 to $15 \mathrm{~g} / \mathrm{L}$ ) and PPI03 (from approximately 1 to $10 \mathrm{~g} / \mathrm{L}$ ) in each buffer were prepared and measured as described above. The interaction parameter was calculated using the expansion of the apparent diffusion coefficient:

$$
\mathrm{D}=\mathrm{D}_{0}\left(1+\mathrm{kDC}_{\mathrm{D}}\right)
$$

where $\mathrm{D}_{0}$ denotes the diffusion coefficient of an isolated scattering solute molecule in a solvent and $\mathrm{c}$ is the protein concentration. The linear fits of the concentration dependence of $D_{0}$ from which $k_{D}$ was determined can be found in the supplementary data (Fig S3 and Fig S4)

\section{Differential Scanning Fluorimetry (DSF)}

All samples were diluted to a protein concentration of $1 \mathrm{~g} / \mathrm{L}$ with the respective buffer and filled into $9 \mu \mathrm{L}$ microcuvette arrays (Unchained Labs, USA). The Optim® 1000 system (Unchained Labs, USA) was used to apply a temperature ramp of $1{ }^{\circ} \mathrm{C} / \mathrm{min}$ starting from $25^{\circ} \mathrm{C}$ and ending at $100{ }^{\circ} \mathrm{C}$. Protein fluorescence spectra were collected during the ramp after excitation at $266 \mathrm{~nm}$. The system software was used to calculate the intrinsic fluorescence intensity ratio from the fluorescence intensity at $350 \mathrm{~nm}$ and $330 \mathrm{~nm}(\mathrm{~F} 350 / 330)$ against temperature. The protein melting temperatures $\left(\mathrm{T}_{\mathrm{m}}\right)$ were determined 
from the maximum of the first derivatives of these graphs using the Optim® 1000 software (Avacta Analytical, United Kingdom). $T_{\mathrm{m} 1}$ was assigned to the transition at lower temperature and $\mathrm{T}_{\mathrm{m} 2}$ was assigned to the transition at a higher temperature.

\section{Statistical Data Analysis and Comparison}

The mean values, standard deviations, $95 \%$ lower confidence interval (LowCl) and $95 \%$ upper confidence interval $(\mathrm{UpCl})$ of the means were calculated with Origin 2018. A significant difference between two values was considered when the $95 \%$ confidence intervals of two means were not overlapping. In the case of slightly overlapping confidence intervals, we could not prove a significant difference, although the lack of such cannot be confirmed due to the small samples size and the approach we used 22 .

\section{Results and Discussion}

\section{Protein Aggregation and $\mathbf{R}_{\mathrm{h}}$ after Dilution from Different Concentrations of Guanidine Hydrochloride}

The $\mathrm{R}_{\mathrm{h}}$ of LMU-1 and PPI03 after incubation with different concentration of guanidine hydrochloride and subsequent dilution is dependent not only on the denaturant concentration but also on the formulation used (Fig $2 \mathrm{~A}$ and $2 \mathrm{~B}$ ). The increase in the $\mathrm{R}_{\mathrm{h}}$ is due to the formation of more (and/or larger) soluble aggregates, which was confirmed with size exclusion chromatography coupled to multi-angle light scattering detector (see Fig S6 in the supplementary data). The differences in the $R_{h}$ are most pronounced after dilution from $3 \mathrm{M}$ guanidine hydrochloride for both proteins. A comparison between the different LMU-1 samples diluted from $3 \mathrm{M}$ guanidine hydrochloride shows that the lowest $R_{\mathrm{h}}$ is measured in $10 \mathrm{mM}$ histidine $\mathrm{pH} 5.75$ with a mean value of $19.43 \mathrm{~nm}$ and a lower and upper $95 \%$ confidence interval of $18.81 \mathrm{~nm}$ and $20.06 \mathrm{~nm}$ respectively, followed by $10 \mathrm{mM}$ citrate $\mathrm{pH} 5.75$ (Mean $=24 \mathrm{~nm}$ with LowCl $=23.1 \mathrm{~nm}$ and $\mathrm{UpCl}=24.89 \mathrm{~nm}$ ), $10 \mathrm{mM}$ histidine $\mathrm{pH} 5$ (Mean = $29.6 \mathrm{~nm}$ with LowCl $=27.86 \mathrm{~nm}$ and $\mathrm{UpCl}=31.34 \mathrm{~nm})$ and $10 \mathrm{mM}$ citrate $\mathrm{pH} 5($ Mean $=43.1 \mathrm{~nm} \mathrm{LowCl}=40.08 \mathrm{~nm}$ and $\mathrm{UpCl}=46.11 \mathrm{~nm})(\mathrm{Fig} 2 \mathrm{~A})$. Similar observations are made for PPI03 (Fig 2B). In the case of PPI03 the following means and $95 \%$ confidence intervals of the hydrodynamic radius after dilution from $3 \mathrm{M}$ GuHCl were measured - in $10 \mathrm{mM}$ histidine $\mathrm{pH} 5.75$ (Mean $=5.37 \mathrm{~nm}$; $\mathrm{LoCl}=5.22 \mathrm{~nm} ; \mathrm{UpCl}=5.51$ $\mathrm{nm}$ ), in $10 \mathrm{mM}$ citrate pH 5.75 (Mean $=5.97 \mathrm{~nm}$; LoCl $=5.82 \mathrm{~nm} ; \mathrm{UpCl}=6.11 \mathrm{~nm}$ ), in $10 \mathrm{mM}$ histidine pH 5 (Mean $=6.87 \mathrm{~nm} ; \mathrm{LoCl}=6.72 \mathrm{~nm} ; \mathrm{UpCl}=7.01 \mathrm{~nm})$ and in in $10 \mathrm{mM}$ citrate pH 5 (Mean $=7.43$ $\mathrm{nm} ; \mathrm{LoCl}=7.29 \mathrm{~nm} ; \mathrm{UpCl}=7.58 \mathrm{~nm}$ ). The PDI of all samples is between 0.05 and 0.2 when the proteins are diluted from up to $1 \mathrm{M} \mathrm{GuHCl}$, while the PDI of all samples diluted from $3 \mathrm{M}$ or more $\mathrm{GuHCl}$ is between 0.2 and 0.4. An example of the ACFs with the corresponding cumulant fits and the size distribution from the regularization analysis can be found in the supplementary data (Fig S8). Important to mention, none of the samples formed a pellet of insoluble matter after dilution and centrifugation. In addition, the absorption of the protein in the supernatant was measured at $280 \mathrm{~nm}$ and no loss of soluble protein was observed (data not shown). Also, the $R_{h}$ in the samples after 24 hours of incubation in $\mathrm{GuHCl}$ prior to dilution is measured and can be found in the supplementary data (Fig S7). Further, we studied whether the $\mathrm{R}_{\mathrm{h}}$ changes during longer incubation time and found no significant differences in the $\mathrm{R}_{\mathrm{h}}$ of the samples for up to 1 week after dilution from $\mathrm{GuHCl}$ (data not shown).

\section{Isothermal Chemical Denaturation}

The isothermal chemical denaturation graphs obtained with the intrinsic protein fluorescence intensity ratio (F350/330) show that both mAbs exhibit complex unfolding behaviour which fits well to a threestate transition model (see Fig S1 and S2 in the supplementary data). A visual observation of the ICD graphs shows that higher concentration of guanidine hydrochloride is needed to unfold both proteins at $\mathrm{pH} 5.75$ compared to $\mathrm{pH} 5$ (Fig 2A and 2B), which indicates higher resistance to the GuHCl-induced unfolding of the mAbs at the higher $\mathrm{pH}$. To further support this statement, in the case of LMU-1, the mean $\mathrm{C}_{\mathrm{m} 2}$ values are significantly higher at $\mathrm{pH} 5.75$ compared to $\mathrm{pH} 5$ with non-overlapping confidence intervals (Tab 1A). In the case of PPI03, the difference between the $\mathrm{C}_{\mathrm{m} 2}$ in $10 \mathrm{mM}$ histidine $\mathrm{pH} 5$ and 10 
$\mathrm{mM}$ histidine $\mathrm{pH} 5.75$ is also significant, although the same statement is difficult to make for the results in $10 \mathrm{mM}$ citrate due to the slightly overlapping confidence intervals (Tab 1B). Comparing the apparent $\mathrm{dG}$ values at different $\mathrm{pH}$ values reveals that in the case of LMU-1 there is a significant difference (nonoverlapping confidence intervals) between the $\mathrm{dG}$ measured in $10 \mathrm{mM}$ citrate $\mathrm{pH} 5$ and in $10 \mathrm{mM}$ citrate $\mathrm{pH} 5.75$, which indicates higher conformational stability of LMU-1 at the higher $\mathrm{pH}$. In the case of PPI03, although the mean values for the dG differ at $\mathrm{pH} 5$ and $\mathrm{pH} 5.75$, a significant difference cannot be proved due to the overlapping confidence intervals (Tab 1B). Further, the ICD graphs of the proteins obtained in histidine or citrate with the same pH almost completely overlap (Fig 2C and 2D). Important to note, when comparing the stability of the two mAbs in $10 \mathrm{mM}$ citrate or $10 \mathrm{mM}$ histidine with the same $\mathrm{pH}$, there is not a single case in which a significant difference between ICD data obtained at the same $\mathrm{pH}$ can be confirmed due to the overlapping confidence intervals (Tab 1A and 1B).

\section{Colloidal Stability of the mAbs in Different Buffers}

The colloidal stability of both mAbs in citrate and histidine buffer was assessed by means of the interaction parameter $\mathrm{K}_{\mathrm{D}}$. It has been shown that $\mathrm{K}_{\mathrm{D}}$ describes the interparticle interaction in protein solution ${ }^{23}$. Highly positive $k_{D}$ is attributed to repulsive interactions, whereas highly negative is related to attractive interactions ${ }^{24}$. The $\mathrm{K}_{\mathrm{D}}$ of both LMU-1 and PPI03 is positive in histidine buffer and negative in citrate buffer (Tab 1A and 1B). This indicates that both proteins have higher colloidal stability in $10 \mathrm{mM}$ histidine buffer compared to $10 \mathrm{mM}$ citrate in the studied $\mathrm{pH}$ range. However, the $\mathrm{k}_{\mathrm{D}}$ is not a parameter that can assess the conformational stability of the protein and it is demonstrated that both the conformational and colloidal protein stability is important for the aggregate formation in solution 25 .

\section{Thermal Stability of the mAbs in Different Buffers}

Both LMU-1 and PPI03 have higher melting temperatures $\left(\mathrm{T}_{\mathrm{m} 1}\right)$ at $\mathrm{pH} 5.75$ compared to $\mathrm{pH} 5$ (Tab $1 \mathrm{~A}$ and $1 \mathrm{~B}$ ). This indicates higher physical stability of both $\mathrm{mAbs}$ at $\mathrm{pH} 5.75$ and corresponds well to the higher concentration guanidine hydrochloride needed to unfold both proteins at higher $\mathrm{pH}$. The mean values of the melting temperatures of both proteins in histidine almost always appear lower compared to citrate counterparts most probably due to the buffer $\mathrm{pH}$ shift of histidine during heating ${ }^{7}$. However, a significant difference between the melting temperatures of the mAbs in either $10 \mathrm{mM}$ citrate or $10 \mathrm{mM}$ histidine with the same $\mathrm{pH}$ cannot be proved due to the small sample size and the overlapping confidence intervals (Tab 1A and 1B). The thermal denaturation graphs of each mAb sample can be found in the supplementary data (Fig S5).

\section{The Relation Between the $\mathbf{R}_{\mathrm{h}}$ after Dilution from GuHCl and Other Parameters}

The increase of $R_{h}$ after dilution from a certain concentration of guanidine hydrochloride (in our case 3 M) will depend on the degree of protein unfolding at these conditions. In the case of LMU-1 and PPI03 samples with $\mathrm{pH} \mathrm{5}$, the isothermal chemical denaturation curves are shifted to lower denaturant concentrations compared to samples with $\mathrm{pH} 5.75$, which indicates a lower resistance to the $\mathrm{GuHCl}-$ induced unfolding of these proteins at the lower pH (Fig 2C and 2D). Respectively, a higher $\mathrm{R}_{\mathrm{h}}$ (more and larger aggregates formed) is measured after dilution from $3 \mathrm{M}$ guanidine hydrochloride in buffers with $\mathrm{pH} 5$ compared to dilution in buffers with pH 5.75 (Fig 2A and 2B).

When the degree of protein unfolding (or structural perturbation) at a given denaturant concentration is the same (e.g. buffers with the same $\mathrm{pH}$ or higher denaturant concentrations where the protein is fully unfolded regardless of the $\mathrm{pH}$ i.e. at $4 \mathrm{M} \mathrm{GuHCl}$ ), the protein aggregation and the measured $\mathrm{R}_{\mathrm{h}}$ after dilution will depend mostly on the colloidal stability and the aggregation propensity of the (partially) unfolded protein after dilution in these conditions. For example, the ICD curves of LMU-1 in citrate or histidine buffer with the same pH almost completely overlap (Fig 2C and 2D). However, the $\mathrm{Rh}_{\mathrm{h}}$ of LMU1 after dilution from $3 \mathrm{M} \mathrm{GuHCl}$ is always lower in histidine buffer compared to citrate counterparts with the same $\mathrm{pH}$ (Fig 2A). Similar observations are made also with the other mAb - PPI03 (Fig 2B). Also, at $4 \mathrm{M} \mathrm{GuHCl}$, there is the same degree of unfolding (according to the intrinsic protein fluorescence ratio - Fig $2 \mathrm{C}$ and 2D) for both proteins regardless of the formulation $\mathrm{pH}$ and buffer. Our assumption is that 
in this case the aggregation after dilution will be driven mostly by differences in the protein colloidal stability and we see that the $R_{h}$ after dilution of the proteins from $4 \mathrm{M} \mathrm{GuHCL}$ is always lower in histidine compared to citrate, regardless of the $\mathrm{pH}$. This behaviour is in good agreement with the high $\mathrm{k}_{\mathrm{D}}$ values of both proteins in histidine which indicates a higher protein colloidal stability in this buffer in comparison to citrate.

\section{Effect of Different Additives on the Change in the $\mathbf{R}_{\mathrm{h}}$ after Dilution from GuHCl}

We further tested if the herein proposed approach could be used to study the effect of different additives (i.e. $200 \mathrm{mM}$ sucrose, $200 \mathrm{mM}$ trehalose, $200 \mathrm{mM}$ arginine hydrochloride or $200 \mathrm{mM}$ proline) on the increase in $R_{h}$ (i.e. aggregation) of the mAbs after dilution from $\mathrm{GuHCl}$. To study this, we focused on dilution from $3 \mathrm{M}$ guanidine hydrochloride since this was the concentration of denaturant where we observed the largest differences in the earlier experiments. Next, we performed the dilution in a buffer i.e. $10 \mathrm{mM}$ histidine $\mathrm{pH} 5$, in which the physical stability of both mAbs is neither the worst nor the best according to the different techniques we used in this work. We reported the effect of the additives as the difference in the $\mathrm{R}_{\mathrm{h}}$ after dilution with the additive compared to dilution without an additive (Figure 3). We observed that for both LMU-1 and PPI03 all additives tested were significantly better compared to the histidine buffer alone (Figure 3). However, in the case of LMU-1 $200 \mathrm{mM}$ sucrose and $200 \mathrm{mM}$ arginine chloride caused the largest decrease in the $R_{h}$ i.e. the highest stabilizing effect (Figure 3 - Left), while in the case of PPI03 $200 \mathrm{mM}$ sucrose and $200 \mathrm{mM}$ trehalose were the most stabilizing excipients according to the proposed approach (Figure 3 - Right).

\section{Conclusion and Outlook}

In this work, we demonstrated with two mAbs that the DLS assessment of the aggregation (by means of the $\mathrm{Rh}$ ) after dilution from different concentrations of guanidine hydrochloride is a promising approach to probe the protein physical stability in different formulations.

A formulator would then aim to i) find buffers and $\mathrm{pH}$ that shift the increase in $\mathrm{R}_{\mathrm{h}}$ after dilution to higher guanidine hydrochloride concentrations (i.e. find conditions that provide higher resistance to guanidine hydrochloride unfolding); and ii) find conditions that minimize $\mathrm{R}_{\mathrm{h}}$ dilution (i.e. find conditions that provide higher colloidal stability and less aggregation during dilution from a denaturant);

The proposed method could be used alone or as a complementary technique. If used alone, we suggest that at least several guanidine hydrochloride concentrations (in a step of 0.5 or $1 \mathrm{M}$ ) are tested to find conditions where the increase in the $\mathrm{R}_{\mathrm{h}}$ is largest after dilution. Next, this denaturant concentration could be used to test the influence of different buffers and additives on the increase in the $\mathrm{Rh}$. In the case of the antibodies that we tested, such denaturant concentration is usually around $3 \mathrm{M}$ guanidine hydrochloride.

Alternatively, the method we show could be used as a complementary technique to isothermal chemical denaturation (e.g. to distinguish if there is a difference in the protein physical stability in conditions that exhibit overlapping curves in an isothermal chemical denaturation experiment). In such case, we suggest that the concentration of guanidine hydrochloride that can be used is around the denaturant concentration where the protein is partially unfolded according to the ICD experiment.

The approach we propose offers a unique combination of features: $i)$ the method is isothermal (problems arising from sample heating are avoided); ii) it can distinguish between overlapping curves in an ICD experiment due to the different colloidal stability and different level of aggregation after dilution from such samples; iii) the method is label-free and independent of the intrinsic protein fluorescence; iv) very short instrument measurement time for one sample is required; v) there is a high potential for scale down and automatization with the help of already available equipment in many protein formulation laboratories; 


\section{Acknowledgements}

This study was funded by a project part of the EU Horizon 2020 Research and Innovation programme under the Marie Skłodowska-Curie grant agreement No 675074.

The authors are grateful to Jens Thostrup Bukrinsky, Pernille Harris, Andreas Tosstorff, Matja Zalar and Martin Domnowski for the helpful discussions during the process of making this manuscript.

\section{Conflict of Interests}

L.G. and D.R. are employees of Wyatt Technology Europe GmbH.

\section{References}

1. Johnson CM. Differential scanning calorimetry as a tool for protein folding and stability. Arch Biochem Biophys. 2013;531(1):100-109. doi:http://dx.doi.org/10.1016/j.abb.2012.09.008

2. Brader ML, Estey $\mathrm{T}$, Bai S, et al. Examination of thermal unfolding and aggregation profiles of a series of developable therapeutic monoclonal antibodies. Mol Pharm. 2015;12(4):1005-1017. doi:10.1021/mp400666b

3. Thiagarajan G, Semple A, James JK, Cheung JK, Shameem M. A comparison of biophysical characterization techniques in predicting monoclonal antibody stability. MAbs. 2016;8(6):10881097. doi:10.1080/19420862.2016.1189048

4. He F, Hogan S, Latypov RF, Narhi LO, Razinkov VI. High throughput thermostability screening of monoclonal antibody formulations. J Pharm Sci. 2010;99(4):1707-1720. doi:10.1002/jps.21955

5. Freire E, Schön A, Hutchins BM, Brown RK. Chemical denaturation as a tool in the formulation optimization of biologics. Drug Discov Today. 2013;18(19-20):1007-1013. doi:10.1016/j.drudis.2013.06.005

6. Sanchez-Ruiz JM. Theoretical analysis of Lumry-Eyring models in differential scanning calorimetry. Biophys J. 1992;61(4):921-935. doi:10.1016/S0006-3495(92)81899-4

7. Svilenov H, Markoja U, Winter G. Isothermal chemical denaturation as a complementary tool to overcome limitations of thermal differential scanning fluorimetry in predicting physical stability of protein formulations. Eur J Pharm Biopharm. 2018;125:106-113. doi:10.1016/j.ejpb.2018.01.004

8. Perez-Riba A, Itzhaki LS. A method for rapid high-throughput biophysical analysis of proteins. Sci Rep. 2017;7(1):1-6. doi:10.1038/s41598-017-08664-w

9. Ross $\mathrm{P}$, Weihofen W, Siu F, et al. Isothermal chemical denaturation to determine binding affinity of small molecules to G-protein coupled receptors. Anal Biochem. 2015;473:41-45. doi:10.1016/j.ab.2014.11.019

10. Freire B. ( 12 ) United States Patent. 2013;1(12):0-4. doi:10.1016/j.(73)

11. Wafer L, Kloczewiak M, Polleck SM, Luo Y. Isothermal chemical denaturation of large proteins: Path-dependence and irreversibility. Anal Biochem. 2017;539:60-69. doi:10.1016/j.ab.2017.10.001

12. Temel DB, Landsman P, Brader ML. Orthogonal Methods for Characterizing the Unfolding of Therapeutic Monoclonal Antibodies: Differential Scanning Calorimetry, Isothermal Chemical Denaturation, and Intrinsic Fluorescence with Concomitant Static Light Scattering. Vol 567. 1st ed. Elsevier Inc.; 2016. doi:10.1016/bs.mie.2015.08.029 
13. Wanner R, Breitsprecher D, Duhr S, Baaske P, Winter G. Thermo-Optical Protein Characterization for Straightforward Preformulation Development. J Pharm Sci. 2017. doi:10.1016/j.xphs.2017.06.002

14. Bam NB, Cleland JL, Randolph TW. Molten globule intermediate of recombinant human growth hormone: Stabilization with surfactants. Biotechnol Prog. 1996;12(6):801-809. doi:10.1021/bp960068b

15. Yazdanparast R, Esmaeili MA, Khodagholi F. Control of aggregation in protein refolding: Cooperative effects of artificial chaperone and cold temperature. Int J Biol Macromol. 2007;40(2):126-133. doi:10.1016/J.IJBIOMAC.2006.06.018

16. Yasuda M, Murakami Y, Sowa A, Ogino H, Ishikawa $\mathrm{H}$. Effect of additives on refolding of a denatured protein. Biotechnol Prog. 1998;14(4):601-606. doi:10.1021/bp9800438

17. Arora D, Khanna N. Method for increasing the yield of properly folded recombinant human gamma interferon from inclusion bodies. J Biotechnol. 1996;52(2):127-133. doi:10.1016/S01681656(96)01636-7

18. De Bernardez Clark E. Refolding of recombinant proteins. Curr Opin Biotechnol. 1998;9(2):157-163. doi:10.1016/S0958-1669(98)80109-2

19. Ho JGS, Middelberg APJ. Estimating the potential refolding yield of recombinant proteins expressed as inclusion bodies. Biotechnol Bioeng. 2004;87(5):584-592. doi:10.1002/bit.20148

20. Lee S-H, Carpenter JF, Chang BS, Randolph TW, Kim Y. Effects of solutes on solubilization and refolding of proteins from inclusion bodies with high hydrostatic pressure. Protein Sci. 2006;15(2):304-313. doi:10.1110/ps.051813506

21. Lazar KL, Patapoff TW, Sharma VK. Cold denaturation of monoclonal antibodies. MAbs. 2010;2(1):42-52. doi:10.4161/mabs.2.1.10787

22. Austin PC, Hux JE. A brief note on overlapping confidence intervals. J Vasc Surg. 2002;36(1):194-195. doi:10.1067/MVA.2002.125015

23. Zhang J, Liu XY. Effect of protein - protein interactions on protein aggregation kinetics. 2003;119(20):10972-10976. doi:10.1063/1.1622380

24. Menzen TA. Temperature-Induced Unfolding, Aggregation, and Interaction of Therapeutic Monoclonal Antibodies. 2014.

25. Chi EYE, Krishnan S, Kendrick BBS, Chang BS, Carpenter JF, Randolph TW. Roles of conformational stability and colloidal stability in the aggregation of recombinant human granulocyte colony-stimulating factor. Protein Sci. 2003;12(5):903-913.

doi:10.1110/ps.0235703.mer 


\section{Figure legend}

Figure 1. Schematic explanation of the working hypothesis - Impact of the physical stability of a $\mathrm{mAb}$ on the protein aggregation after incubation and subsequent dilution from a denaturant.

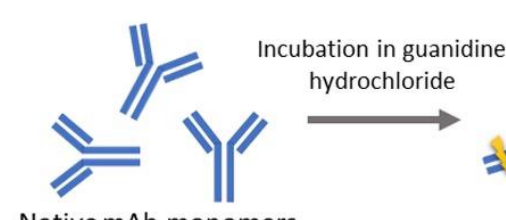

Native mAb monomers<smiles>CC(C)(C)C1CCCCC1</smiles><smiles>C1=CC2=CCC(=C1)C2</smiles>

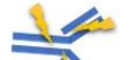

mAb monomers with perturbed structure detected by intrinsic protein fluorescence changes
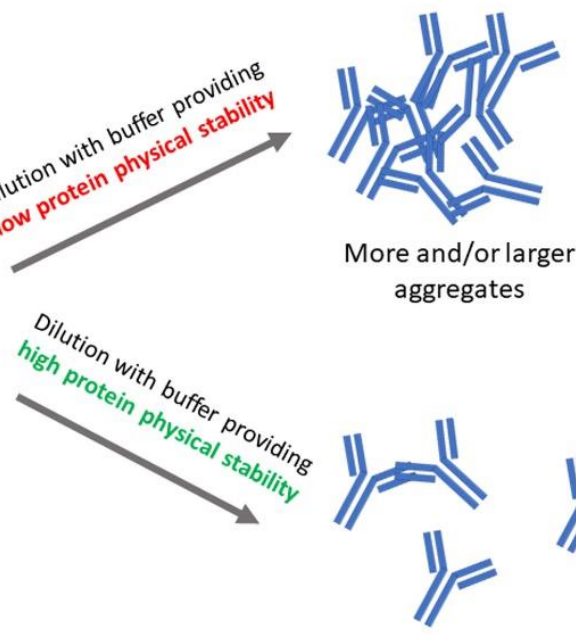

Less and/or smaller protein aggregates 
Figure 2. Hydrodynamic radius $\mathrm{Rh}$ from dynamic light scattering of LMU-1 (A) and PPI03 (B) after incubation and dilution from different concentrations of guanidine hydrochloride in 10 $\mathrm{mM}$ histidine pH 5 (red squares), $10 \mathrm{mM}$ histidine pH 5.75 (blue circles), $10 \mathrm{mM}$ citrate pH 5 (yellow diamonds), and $10 \mathrm{mM}$ citrate $\mathrm{pH} 5.75$ (green triangles). The protein concentration in the measured samples in (A) and (B) is $1 \mathrm{~g} / \mathrm{L}$ and $0.2 \mathrm{~g} / \mathrm{L}$ for LMU-1 and PPI03 respectively; Isothermal unfolding of LMU-1 (C) and PPI03 (D) in presence of different concentrations of guanidine hydrochloride measured by the change in the intrinsic protein fluorescence intensity ratio (F350/330). The protein concentration in the measured samples in (C) and (D) is $1 \mathrm{~g} / \mathrm{L}$ and $0.5 \mathrm{~g} / \mathrm{L}$ for LMU-1 and PPI03 respectively;
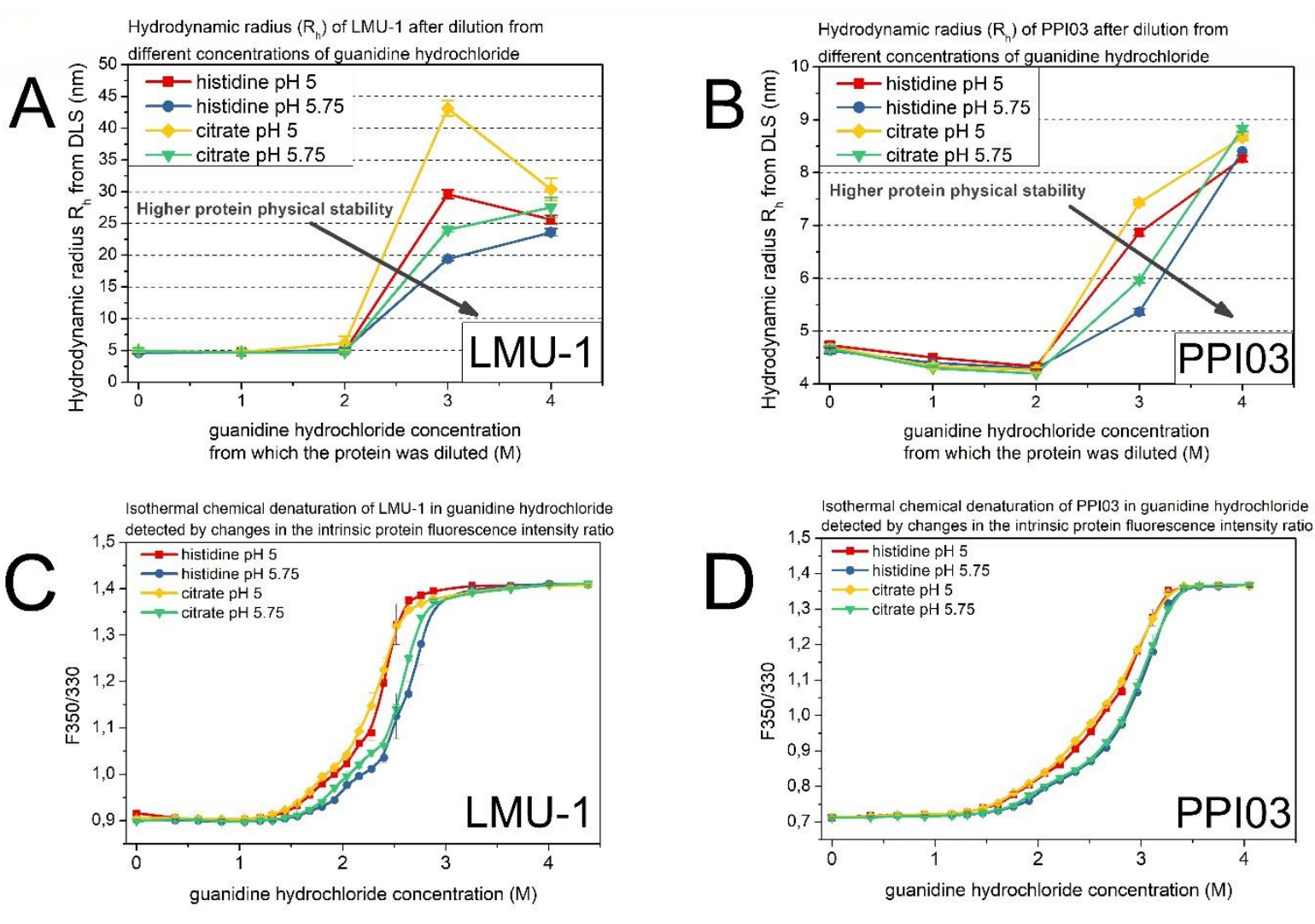
Figure 3. Effect of various additives on the change in the hydrodynamic radius $R_{h}$ from DLS of LMU-1 (left) and PPI03 (right) after dilution from $3 \mathrm{M}$ guanidine hydrochloride in $10 \mathrm{mM}$ histidine pH 5. All measurements were corrected for viscosity as described in Materials and methods. For clarity reasons, the values with additives are represented as a difference from the value without an additive. Negative values indicate that the $R_{h}$ is lower after dilution with the additive compared to dilution without an additive. The circles represent the mean value of the measurements, the bars represent the upper and lower $95 \%$ confidence intervals. The final protein concentration after dilution is $1 \mathrm{~g} / \mathrm{L}$ for both LMU-1 and PPI03.

Effect of different additives on the change in the hydrodynamic radius of LMU-1 after dilution from $3 \mathrm{M}$ guanidine hydrochloride in $10 \mathrm{mM}$ histidine $\mathrm{pH} 5$

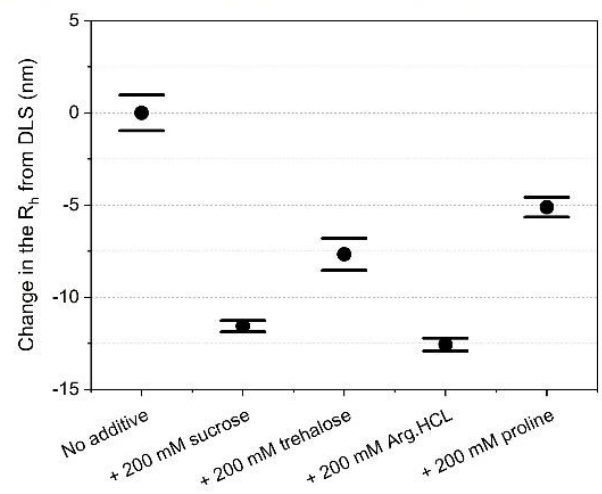

Effect of different additives on the change in the hydrodynamic radius of PPI03 after dilution from $3 \mathrm{M}$ guanidine hydrochloride in $10 \mathrm{mM}$ histidine $\mathrm{pH} 5$

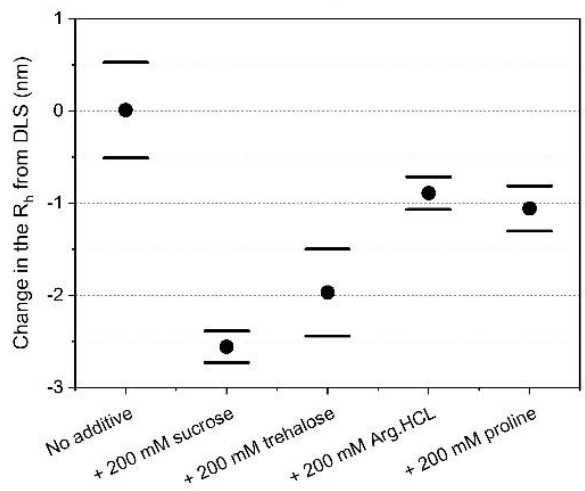


Table 1. Physical stability parameters of LMU-1 (A) and PPI03 (B) in different buffers and pH. The apparent Gibbs free energy of unfolding (dG) and the melting denaturant concentrations for the first and second unfolding $\left(C_{m 1}\right.$ and $\left.C_{m 2}\right)$ are obtained with isothermal chemical denaturation as described in Materials and methods. The melting temperatures of the protein $\left(T_{\mathrm{m} 1}\right.$ and $\left.T_{\mathrm{m} 2}\right)$ are obtained from the maximum of the first derivative of the protein unfolding measured with differential scanning fluorimetry as described in Materials and methods. All values (except the $\mathrm{K}_{\mathrm{D}}$ ) are means of triplicates and the $95 \%$ lower and $95 \%$ upper confidence intervals are reported in the brackets (Lower $\mathrm{Cl} 95 \%$ - Upper $\mathrm{Cl} 95 \%$ ) next to each mean.

\begin{tabular}{|c|c|c|c|c|c|c|}
\hline Table 1A & \multirow{2}{*}{$\mathrm{dG}, \mathrm{kJ} / \mathrm{mol}$} & \multirow{2}{*}{$C_{m 1}, M$} & \multirow{2}{*}{$\mathrm{C}_{\mathrm{m} 2, \mathrm{M}}$} & \multirow{2}{*}{$\mathrm{k}_{\mathrm{D}}, \mathrm{mL} / \mathrm{g}$} & \multirow{2}{*}{$\mathbf{T}_{\mathrm{m} 1},{ }^{\circ} \mathrm{C}$} & \multirow{2}{*}{$\mathbf{T}_{\mathrm{m} 2,}{ }^{\circ} \mathrm{C}$} \\
\hline LMU-1 & & & & & & \\
\hline histidine pH 5 & $94.91(90.06$ - 99.77) & $1.76(1.61-1.92)$ & $2.44(2.40-2.49)$ & 37.9 & $62.20(61.56-62.83)$ & $77.5(76.90-78.20)$ \\
\hline citrate $\mathrm{pH} 5$ & $76.84(60.35-93.34)$ & $1.67(1.21-2.13)$ & $2.38(2.33-2.43)$ & -1.18 & $63.52(62.17-64.88)$ & $78.5(77.41-79.58)$ \\
\hline histidine pH 5.75 & $106.10(98.70-113.49)$ & $1.92(1.74-2.10)$ & $2.66(2.61-2.72)$ & 40.2 & $66.82(65.09-68.55)$ & $79.7(79.23-80.26)$ \\
\hline citrate $\mathrm{pH} 5.75$ & $111.84(100.98-122.70)$ & $1.94(1.80-2.08)$ & $2.60(2.56-2.63)$ & -8.46 & $68.29(66.41-70.18)$ & $79.3(77.45-81.15)$ \\
\hline Table 1B & \multirow[b]{2}{*}{$\mathrm{dG}, \mathrm{kJ} / \mathrm{mol}$} & \multirow[b]{2}{*}{$C_{m 1}, M$} & \multirow[b]{2}{*}{$\mathrm{C}_{\mathrm{m} 2, \mathrm{M}}$} & \multirow[b]{2}{*}{$\mathrm{k}_{\mathrm{D}}, \mathrm{mL} / \mathrm{g}$} & \multirow[b]{2}{*}{$\mathbf{T}_{\mathrm{m} 1},{ }^{\circ} \mathbf{C}$} & \multirow[b]{2}{*}{$\mathbf{T}_{\mathrm{m} 2},{ }^{\circ} \mathrm{C}$} \\
\hline PPI03 & & & & & & \\
\hline histidine $\mathrm{pH} 5$ & $75.06(63.83-86.29)$ & $1.86(1.62-2.09)$ & $3.00(2.99-3.01)$ & 42 & $62.87(61.48-64.25)$ & $76.4(74.67$ - 78.13) \\
\hline citrate $\mathrm{pH} 5$ & $74.84(50.41-99.27)$ & $1.99(1.79-2.21)$ & $3.01(2.81-3.20)$ & -0.58 & $63.88(63.31-64.44)$ & 77.99 (75.84 - 78.29) \\
\hline histidine $\mathrm{pH} 5.75$ & $87.56(74.70-100.42)$ & $2.28(1.78-2.77)$ & $3.09(3.04-3.14)$ & 46 & $68.26(68.13-68.39)$ & $77.01(77.68-78.30)$ \\
\hline citrate $\mathrm{pH} 5.75$ & $80.03(68.61-91.45)$ & $2.16(1.66-2.67)$ & $3.07(2.93-3.21)$ & -4.8 & $69.17(67.71-70.63)$ & $78.66(77.90-79.42)$ \\
\hline
\end{tabular}




\section{Supplementary data}

\section{"A New Approach to Study the Physical Stability of Monoclonal Antibody Formulations - Dilution from a Denaturant"}

Hristo Svilenov ${ }^{1 *}$, Lorenzo Gentiluomo ${ }^{1,2}$, Wolfgang Friess ${ }^{1}$, Dierk Roessner ${ }^{2}$, Gerhard Winter ${ }^{1}$

${ }^{1}$ Ludwig Maximilians-Universität München, Department of Pharmacy, Pharmaceutical Technology and Biopharmaceutics, Butenandstr. 5, 81377 Munich, Germany

${ }^{2}$ Wyatt Technology Europe GmbH, Hochstrasse 12a, 56307 Dernbach, Germany

*Corresponding author: hrisph@cup.uni-muenchen.de

\section{SUPPLEMENTARY FIGURES:}

Figure S1. Unfolding of LMU-1 by guanidine hydrochloride in different buffers and $\mathrm{pH}$ values. The black points represent the experimentally measured values. The red line is the theoretical fit to a three-state model. The inset shows the corresponding residuals from the fit.
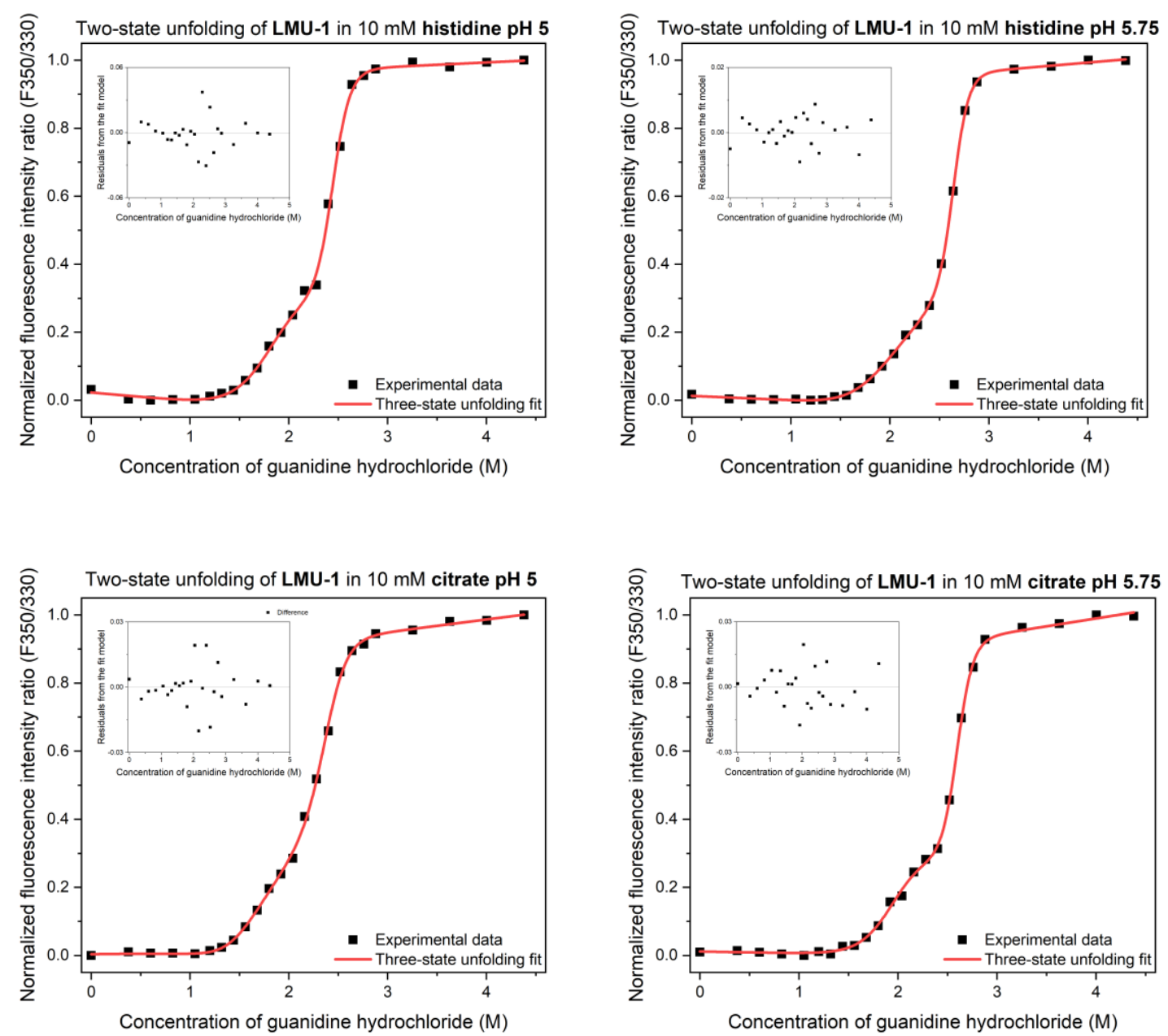
Figure S2. Unfolding of PPI03 by guanidine hydrochloride in different buffers and pH values. The black points represent the experimentally measured values. The red line is the theoretical fit to a three-state model. The inset shows the corresponding residuals from the fit.
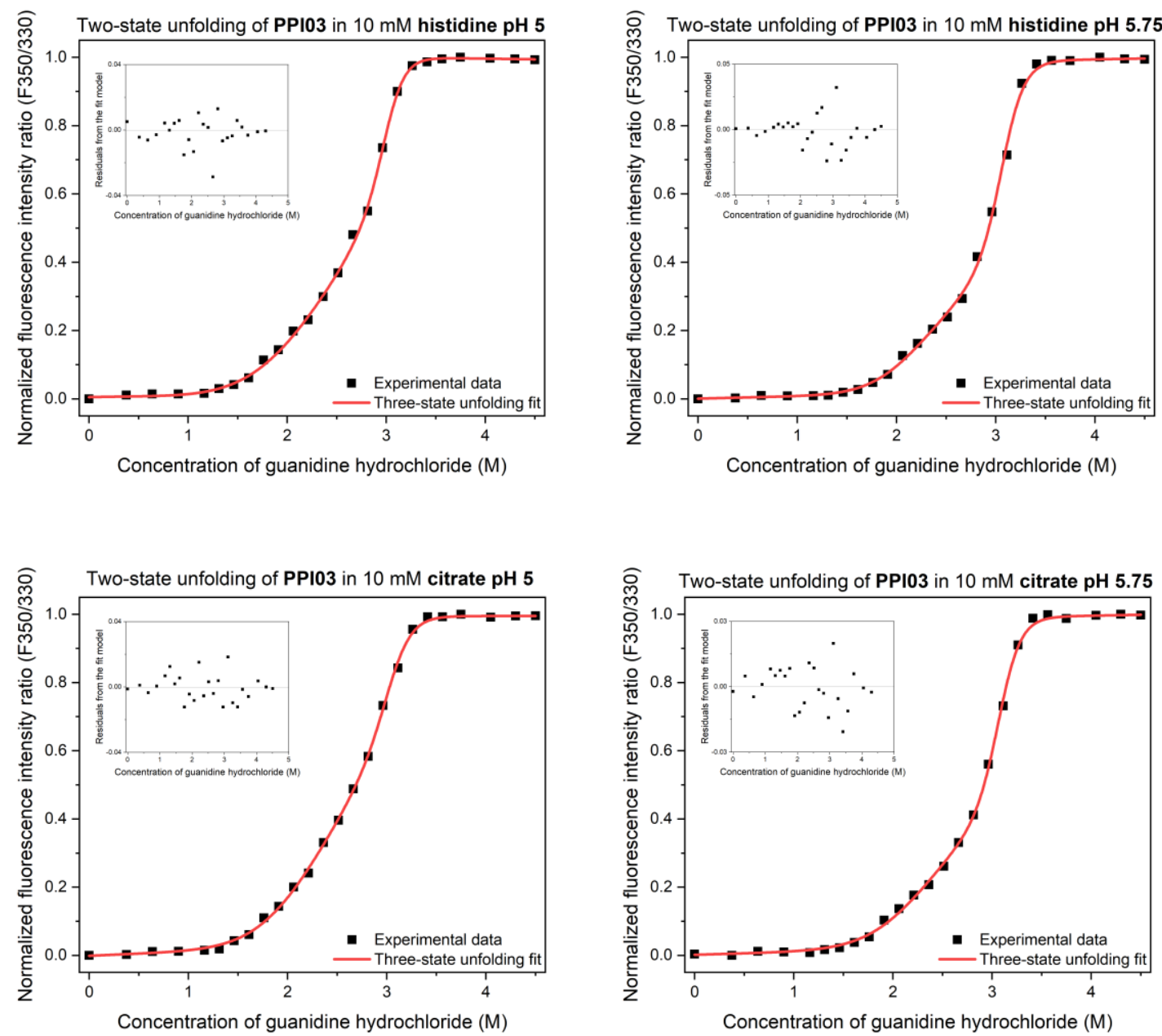
Figure S3. Concentration dependence of the diffusion coefficient of LMU-1 in different buffers and linear fits from which the interaction parameter $k_{D}$ was derived

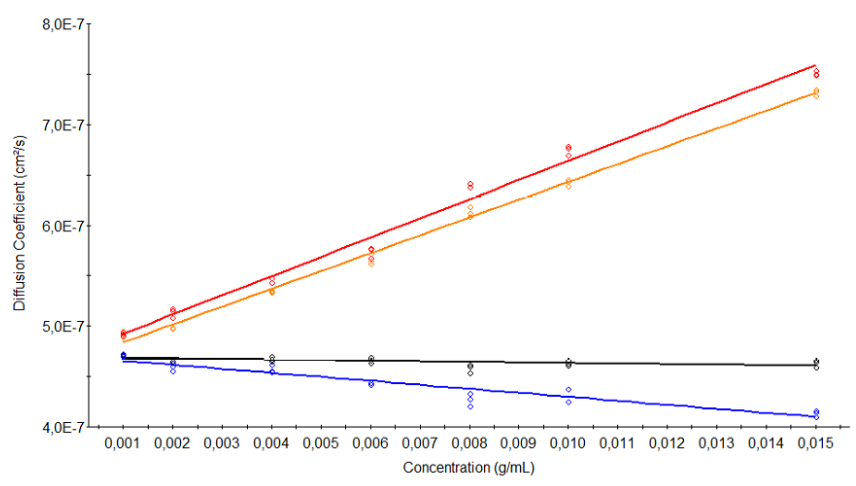

Figure S4. Concentration dependence of the diffusion coefficient of PPI03 in different buffers and linear fits from which the interaction parameter $k_{D}$ was derived

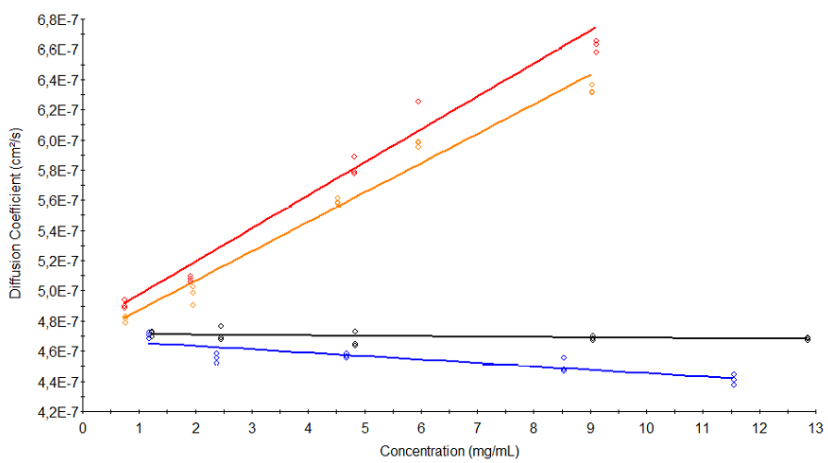

Figure S5. Thermal unfolding curves obtained from the change in the intrinsic protein fluorescence (F350/330) ratio of LMU-1 (left) and PPI03 (Right) during heating in different buffers - $10 \mathrm{mM}$ histidine pH 5 (black squares), $10 \mathrm{mM}$ histidine pH 5.75 (red circles), $10 \mathrm{mM}$ citrate pH 5 (blue triangles up), $10 \mathrm{mM}$ citrate $\mathrm{pH} 5.75$ (green triangles down).
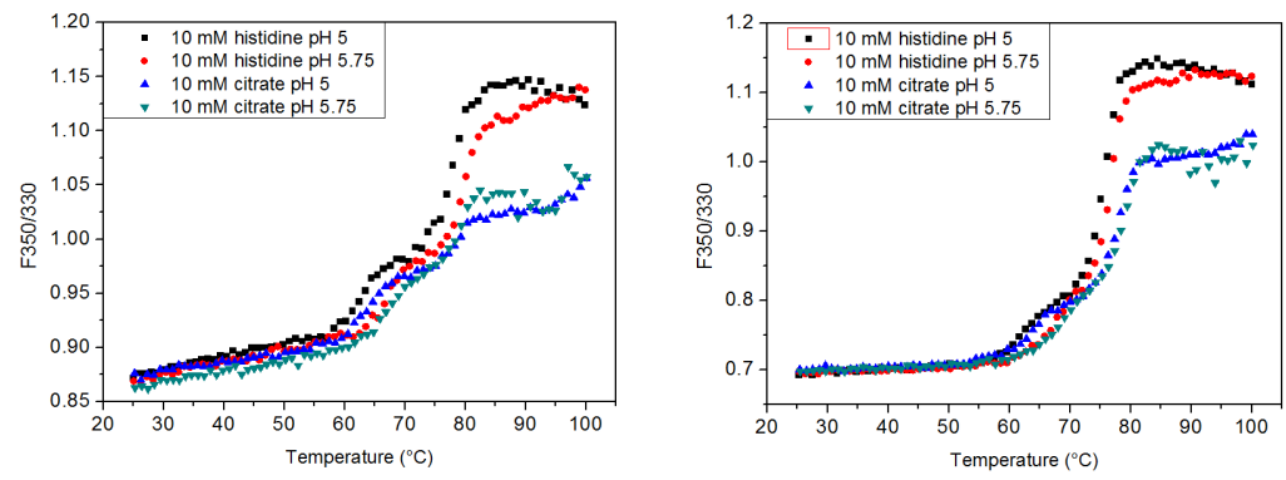
Figure S6. Size exclusion chromatography and multi-angle light scattering with quasi-elastic light scattering detection (SEC-MALS-QELS).

A. Chromatograms of LMU-1 in $10 \mathrm{mM}$ histidine $\mathrm{pH} 5$ after dilution from $0 \mathrm{M}$ (black), $1 \mathrm{M}$ (red), $2 \mathrm{M}$ (blue) and $3 \mathrm{M}$ (green) guanidine hydrochloride - UV detection at $280 \mathrm{~nm}$ (left) and QELS signal (right). The aggregate peak and the light scattering from the aggregate peak increases when LMU-1 is diluted from higher guanidine hydrochloride concentration, which corresponds well to the increase in the $R_{h}$ measured by DLS.
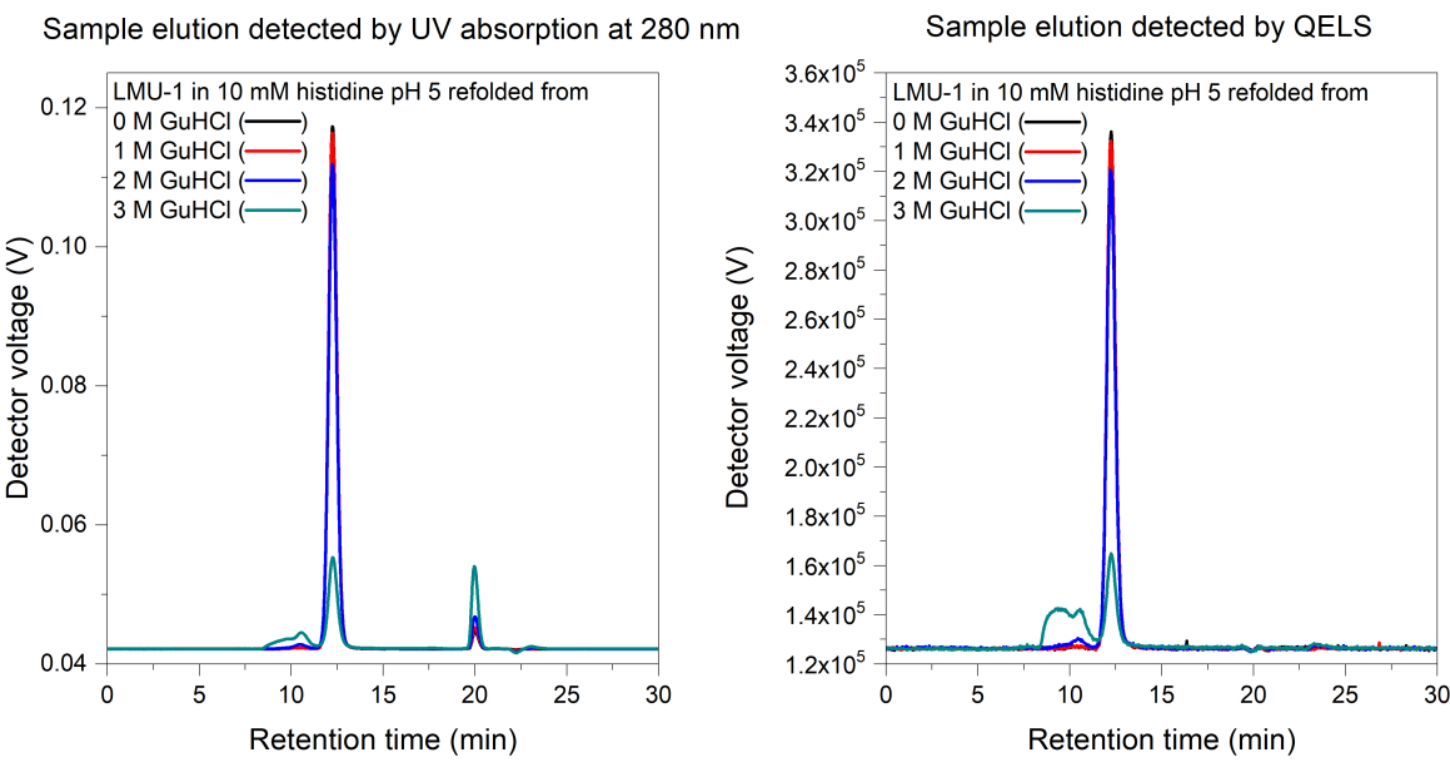

B. Chromatograms of LMU-1 in $10 \mathrm{mM}$ histidine pH 5.75 (black) or $10 \mathrm{mM}$ citrate pH 5.75 (red) after dilution from $3 \mathrm{M}$ guanidine hydrochloride - UV detection at $280 \mathrm{~nm}$ (left) and QELS signal (right). The relative area of the aggregate peak after LMU-1 diluted from either citrate or histidine is similar, but the light scattering from the aggregate peak is higher when LMU-1 is diluted in citrate in comparison to histidine buffer, which indicates that the aggregates formed after dilution in citrate are larger. This corresponds well with the lower $\mathbf{R}_{\mathrm{h}}$ measured by DLS after protein dilution in histidine compared to the $\mathbf{R}_{\mathrm{h}}$ after dilution in citrate.
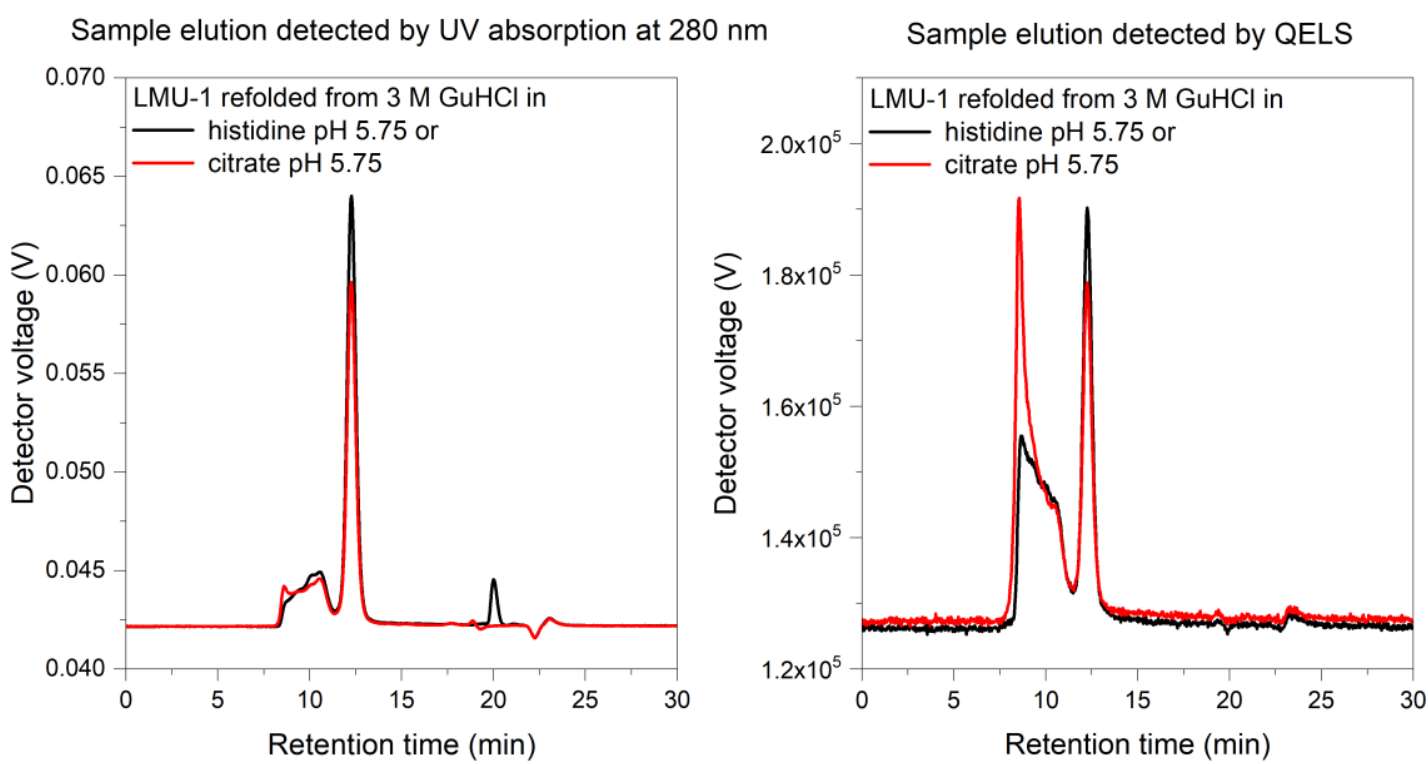


\section{Description of the SEC-MALS-QELS method:}

The system consisted of Agilent 1260 infinity II pump (Agilent G7111B, Santa Clara, CA, USA) with an online degasser (Agilent G7111B), and a temperature controlled autosampler (Agilent G7129A) at $4^{\circ} \mathrm{C}$. The separation was performed with a SUPERDEX 200 INCREASE 10/30 GL column. A TREOS II MALS detector (Wyatt Technology, Santa Barbara, USA) was connected to the system. The MALS detector measured the intensity of the scattered light at 4 scattering angles, 3 angles were used for the static light scattering while the fourth one was used to measure the dynamic light scattering (or quasi elastic light scattering - QELS). In addition, a variable wavelength detector (Agilent G7114A) operated at 280 $\mathrm{nm}$ and a differential refractive index detector (Optilab T-rEX,Wyatt Technology Corp.) were connected to the system. Data collection and processing were performed using the ASTRA software, Version 7.1 (Wyatt Technology, Santa Barbara, USA). The aqueous mobile phase consisted of PBS buffer in HPLCgrade water with $200 \mathrm{ppm}$ of sodium azide (Sigma-Aldrich, St. Louis, USA). The reagent was purum grade and the mobile phase was filtered through Durapore VVPP $0.1 \mathrm{~m}$ membrane filters (Millipore Corporation, Billerica, MA, USA).

Figure S7. Hydrodynamic radii of LMU-1 (left) and PPI03 (Right) measured with DLS after 24 hours of incubation in different concentrations of GuHCL and different buffers - $10 \mathrm{mM}$ histidine pH 5 (red), $10 \mathrm{mM}$ histidine pH 5.75 (blue), $10 \mathrm{mM}$ citrate pH 5 (yellow) and $10 \mathrm{mM}$ citrate pH 5.75 (green). The protein concentration is $10 \mathrm{~g} / \mathrm{L}$ in all LMU-1 samples and $2 \mathrm{~g} / \mathrm{L}$ in all PPI03 samples. The viscosity of the respective GuHCL concentration was measured as described in Materials and methods and used in the calculations of the $R_{h}$. The large differences between the $R_{h}$ of the proteins in the absence of GuHCL are due to effects from the $\mathrm{k}_{\mathrm{D}}$ (see Figure S3 and S4).
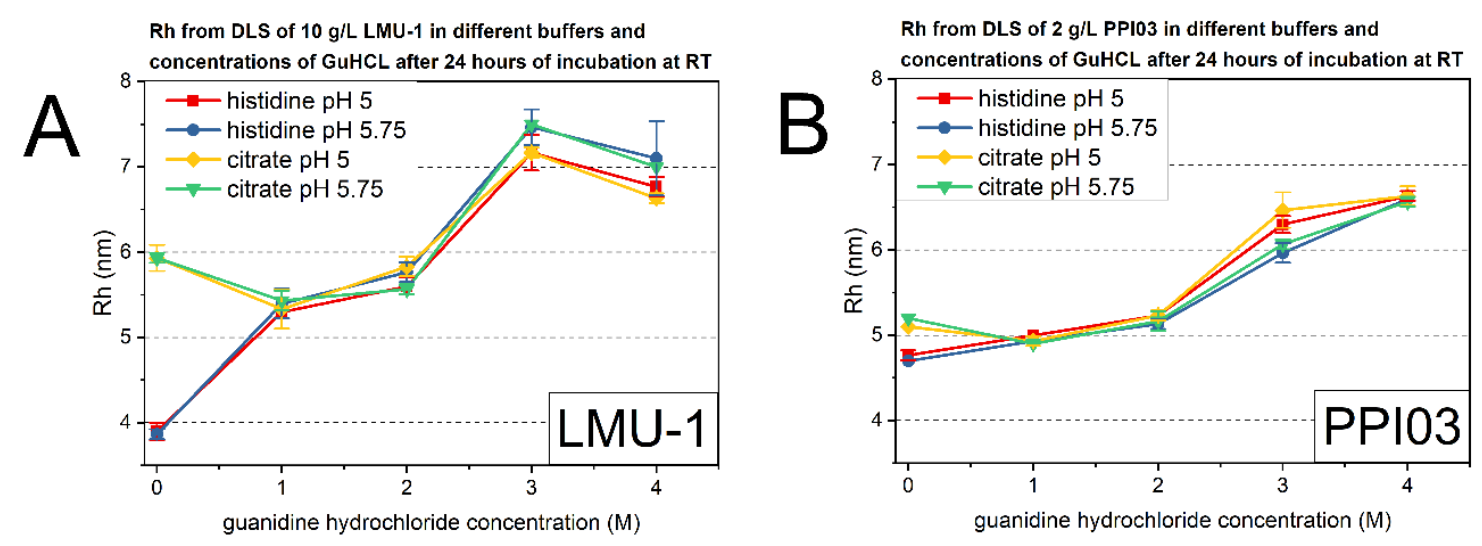
Figure S8. Example of autocorrelation functions and the corresponding cumulant fit (black line) from DLS measurements of LMU-1 (A) and PPI03 (B) samples after dilution from different GuHCL concentrations. Size distributions from the regularization analysis of the LMU-1 (C) and PPI03 (D) samples after dilution from different GuHCL concentrations. All experiments for this figure were performed in $10 \mathrm{mM}$ histidine $\mathrm{pH}$ 5. The concentration of LMU-1 and PPI03 are $1 \mathrm{~g} / \mathrm{L}$ and 0.2 g/L respectively.
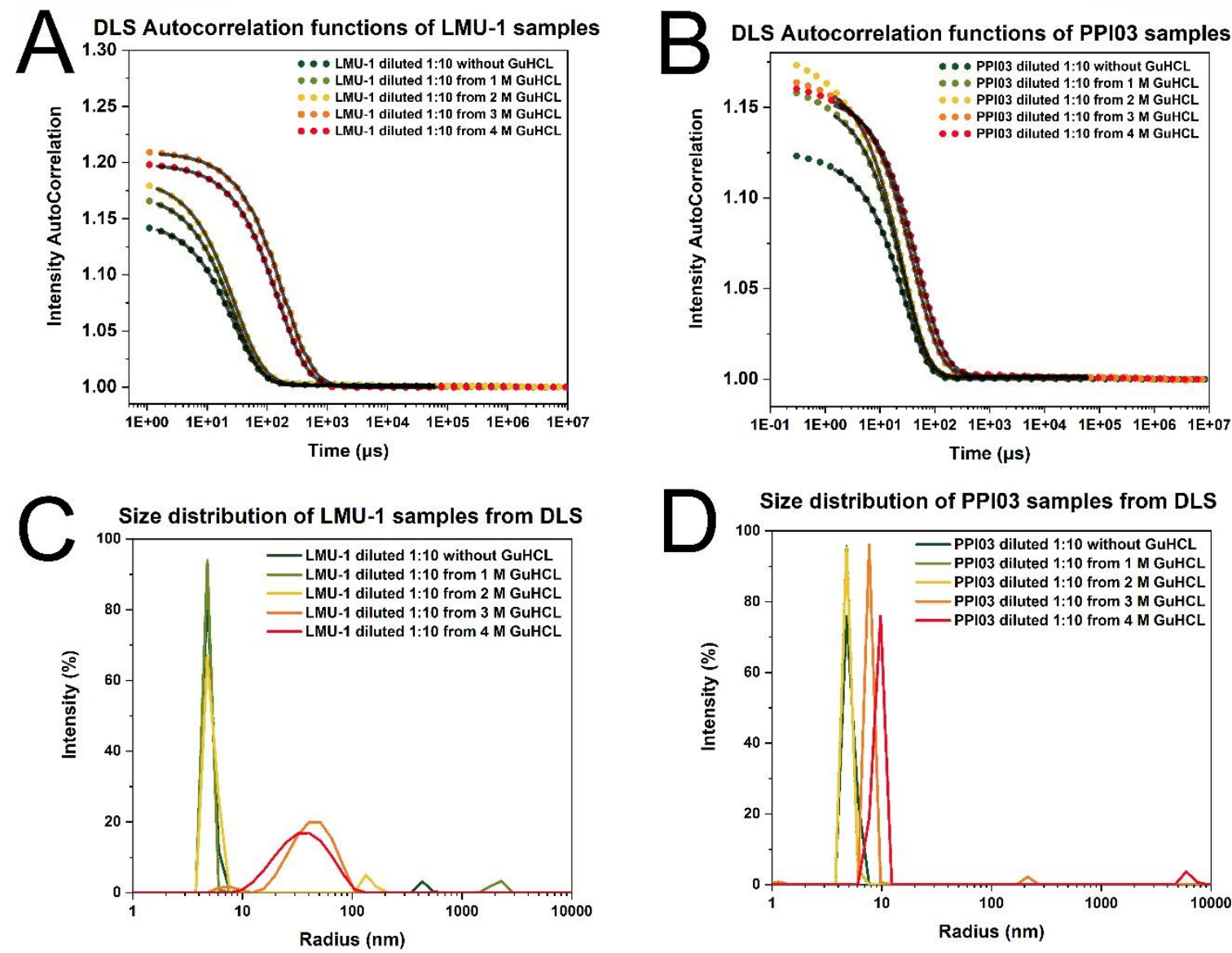


\section{SUPPLEMENTARY TABLES:}

Table S1. Dilution tables for an isothermal chemical denaturation experiment with LMU-1

\begin{tabular}{|c|c|c|c|c|c|}
\hline $\begin{array}{l}\text { Sample } \\
\text { No }\end{array}$ & $\begin{array}{c}\text { Buffer } \\
\text { volume }(\mu \mathrm{L})\end{array}$ & $\begin{array}{c}6 \text { M Guanidine } \\
\text { hydrochloride in } \\
\text { buffer volume } \\
(\mu \mathrm{L})\end{array}$ & $\begin{array}{l}\text { Final guanidine } \\
\text { hydrochloride } \\
\text { concentration (M) }\end{array}$ & $\begin{array}{l}\text { Protein } \\
\text { solution } \\
\text { volume } \\
(\mu \mathrm{L})\end{array}$ & $\begin{array}{c}\text { Total } \\
\text { sample } \\
\text { volume } \\
(\mu \mathrm{L}) \\
\end{array}$ \\
\hline 1 & 72 & 0 & 0 & 8 & 80 \\
\hline 2 & 67 & 5 & 0.38 & 8 & 80 \\
\hline 3 & 64 & 8 & 0.60 & 8 & 80 \\
\hline 4 & 61 & 11 & 0.83 & 8 & 80 \\
\hline 5 & 58 & 14 & 1.05 & 8 & 80 \\
\hline 6 & 56 & 16 & 1.20 & 8 & 80 \\
\hline 7 & 54.4 & 17.6 & 1.32 & 8 & 80 \\
\hline 8 & 52.8 & 19.2 & 1.44 & 8 & 80 \\
\hline 9 & 51.2 & 20.8 & 1.56 & 8 & 80 \\
\hline 10 & 49.6 & 22.4 & 1.68 & 8 & 80 \\
\hline 11 & 48 & 24 & 1.80 & 8 & 80 \\
\hline 12 & 46.4 & 25.6 & 1.92 & 8 & 80 \\
\hline 13 & 44.8 & 27.2 & 2.04 & 8 & 80 \\
\hline 14 & 43.2 & 28.8 & 2.16 & 8 & 80 \\
\hline 15 & 41.6 & 30.4 & 2.28 & 8 & 80 \\
\hline 16 & 40 & 32 & 2.40 & 8 & 80 \\
\hline 17 & 38.4 & 33.6 & 2.52 & 8 & 80 \\
\hline 18 & 36.8 & 35.2 & 2.64 & 8 & 80 \\
\hline 19 & 35.2 & 36.8 & 2.76 & 8 & 80 \\
\hline 20 & 33.6 & 38.4 & 2.88 & 8 & 80 \\
\hline 21 & 28.6 & 43.4 & 3.26 & 8 & 80 \\
\hline 22 & 23.6 & 48.4 & 3.63 & 8 & 80 \\
\hline 23 & 18.6 & 53.4 & 4.01 & 8 & 80 \\
\hline 24 & 13.6 & 58.4 & 4.38 & 8 & 80 \\
\hline
\end{tabular}


Table S2. Dilution tables for an isothermal chemical denaturation experiment with PPI03

\begin{tabular}{|l|c|c|c|c|c|}
\hline $\begin{array}{l}\text { Sample } \\
\text { No }\end{array}$ & $\begin{array}{c}\text { Buffer volume } \\
(\mu \mathrm{L})\end{array}$ & $\begin{array}{c}6 \text { M Guanidine } \\
\text { hydrochloride in } \\
\text { buffer volume }(\mu \mathrm{L})\end{array}$ & $\begin{array}{c}\text { Final guanidine } \\
\text { hydrochloride } \\
\text { concentration } \\
(\mathrm{M})\end{array}$ & $\begin{array}{c}\text { Protein } \\
\text { solution } \\
\text { volume } \\
(\mu \mathrm{L})\end{array}$ & $\begin{array}{c}\text { Total } \\
\text { sample } \\
\text { volume } \\
(\mu \mathrm{L})\end{array}$ \\
\hline 1 & 72 & 0 & 0 & 8 & 80 \\
\hline 2 & 67 & 5 & 0.38 & 8 & 80 \\
\hline 3 & 63.5 & 8.5 & 0.64 & 8 & 80 \\
\hline 4 & 60 & 12 & 0.90 & 8 & 80 \\
\hline 5 & 56.5 & 15.5 & 1.16 & 8 & 80 \\
\hline 6 & 54.5 & 17.5 & 1.31 & 8 & 80 \\
\hline 7 & 52.5 & 19.5 & 1.46 & 8 & 80 \\
\hline 8 & 50.5 & 21.5 & 1.61 & 8 & 80 \\
\hline 9 & 48.5 & 23.5 & 1.76 & 8 & 80 \\
\hline 10 & 46.5 & 25.5 & 1.91 & 8 & 80 \\
\hline 11 & 44.5 & 27.5 & 2.06 & 8 & 80 \\
\hline 12 & 42.5 & 29.5 & 2.21 & 8 & 80 \\
\hline 13 & 40.5 & 31.5 & 2.36 & 8 & 80 \\
\hline 14 & 38.5 & 33.5 & 2.51 & 8 & 80 \\
\hline 15 & 36.5 & 35.5 & 2.66 & 8 & 80 \\
\hline 16 & 34.5 & 37.5 & 2.81 & 8 & 80 \\
\hline 17 & 32.5 & 39.5 & 2.96 & 8 & 80 \\
\hline 18 & 30.5 & 41.5 & 3.11 & 8 & 80 \\
\hline 19 & 28.5 & 43.5 & 3.26 & 8 & 80 \\
\hline 20 & 26.5 & 45.5 & 3.41 & 8 & 80 \\
\hline 21 & 24.5 & 47.5 & 3.56 & 8 & 80 \\
\hline 22 & 22 & 50 & 3.75 & 8 & 80 \\
\hline 23 & 18 & 54 & 4.05 & 8 & 80 \\
\hline
\end{tabular}


https://doi.org/10.1016/j.xphs.2018.08.004 